\section{Examination Of Optic Nerves Using Fundus Photography: Comparison of Patients with Alzheimer's Disease with Elderly Normals}

\author{
Vernon Odom $\mathbf{J}^{\mathbf{1}^{*}}$, Russell Nelson $\mathrm{T}^{2}$, Arnold Adler $\mathbf{S}^{2}$, Angel $\mathbf{R}$. \\ Cruz $^{2}$, Douglas D. McNinch ${ }^{2}$ and Monique J. Leys ${ }^{1}$
}

${ }^{1}$ West Virginia University Eye Institute, Robert C. Byrd Health Science Center of West Virginia University, Morgantown, West Virginia

${ }^{2}$ VA Medical Center, Bay Pines, FL 33504

\begin{abstract}
Background

Eighty percent $(80 \%)$ of patients with Alzheimer's disease (AD) may have reduced numbers of optic nerve (ON) fibers. Therefore, many $A D$ patients should show clinical signs of $\mathrm{ON}$ atrophy on ophthalmoscopic examination.

Methods

We photographed the ONs of 13 patients ( $23 \mathrm{ONs}$ ) with probable $\mathrm{AD}$ and 15 normal patients ( $26 \mathrm{ONs}$ ). An ophthalmologist, masked as to the patients' diagnosis, examined the photographs, measured the cup-to-disc (C/D) ratios and rated the discs as normal, questionable, or atrophied. ON atrophy was indicated by cupping, disc rim pallor, or peripapillary atrophy.

Results

The mean age of the patients with probable $A D$ was $75+9.83$ years and of the normal patients $76.6+13.53$ years. The frequency of rated ON atrophy was greater in the probable AD than the normal patients $(x 2=5.86, p<0.015$ for comparison by eyes; $x 2=5.45, p$ $<0.019$ for comparison by subjects). C/D ratios did not differ between the two groups.

\section{Conclusion}

ON atrophy was present more frequently in patients with $A D$ than in normal patients. Although ON atrophy was not diagnostic of

*Corresponding author: Vernon Odom J, Departments of Ophthalmology and of Physiology and Pharmacology, West Virginia University Eye Institute, 1 Statium Drive, P.O. Box 9193, Morgantown, West Virginia, Tel: 304-598-6959; E-mail: jodom@wvu.edu

Citation: Vernon Odom J, Russell Nelson T, Arnold Adler S , Cruz AR McNinch DD (2014) Examination Of Optic Nerves Using Fundus Photography: Comparison of Patients with Alzheimer's Disease with Elderly Normals. J Ophthalmic Clin Res 1: 003.

Received: July 10, 2014; Accepted: August 25, 2014; Published: August 31, 2014
$A D$, its presence may assist in diagnosing probable $A D .<0.019$ for comparison by subjects). C/D ratios did not differ between the two groups.

Keywords: AD- Alzheimer's disease; ON- Optic nerve; c/d- Cup-to-disc ratio; Fundus photographs; Ophthalmoscopic examination

\section{Introduction}

Alzheimer's disease (AD) is a neural disorder characterized by progressive decline in mental function. Definitive diagnosis is possible only on tissue examination, the brain of $\mathrm{AD}$ patients being characterized by neuritic plaques and neurofibrillary tangles. Living patients are classified as having probable $\mathrm{AD}$ largely by exclusion of other disease processes which produce dementia and mimic $\mathrm{AD}$ [1].

Postmortem studies of patients definitively diagnosed as having $\mathrm{AD}$ have shown that up to $80 \%$ of them have atrophy of the optic nerve $(\mathrm{ON})[2,3]$. Visual functions are abnormal in up to $90 \%$ of patients with probable $\mathrm{AD}[4]$ and the abnormalities are suggestive of $\mathrm{ON}$ involvement in $\mathrm{AD}$, e.g., dyschromatopsia [4,5-7] and contrast sensitivity [5-8]. Other deficits are more consistent with more central problems, e.g., visuospatial ability and depth perception [5-7]. Moreover, visual deficits account for up to $50 \%$ of the variance in low level cognitive tasks in patients with $\mathrm{AD}$ [8]. Therefore, visual deficits in $\mathrm{AD}$ may have a great effect on performance of specific categories of cognitive tasks [8].

Tsai et al. [9] attempted to determine whether optic atrophy was greater in probable $\mathrm{AD}$ than in normals. They employed an automated system for the calculation of the optic disc pallor from photographs and an automated $\mathrm{ON}$ analyzer to measure cup-to-disc (c/d) ratio, cup volume, and other parameters. Although they generally found results which suggested greater $\mathrm{ON}$ atrophy in patients with probable $\mathrm{AD}$, the differences were not statistically significant except in the measurements of the automated ON analyzer [9].

ON degeneration is often detectable on ophthalmologic examination. This suggests that many patients with probable AD will have ON degeneration which is observable ophthalmoscopicly. We wished to test the hypothesis that $\mathrm{ON}$ degeneration should have a higher prevalence on patients diagnosed as having probable $\mathrm{AD}$ on ophthalmoscopic examination. Unfortunately studies involving probable AD patients are difficult for several reasons. First, those with moderate to severe probable $\mathrm{AD}$ may have difficulty in cooperating with study demands. Second, experimenters' who are knowledgeable about the hypothesis may be biased. Third, one must exclude other causes of dementia or of $\mathrm{ON}$ atrophy, e.g., multi-infarct dementia (MID) or glaucoma, to be sure that the classifications of probable $\mathrm{AD}$ and normal are accurate.

To determine the accuracy of our hypothesis that $\mathrm{ON}$ degeneration, detected by ophthalmic examination, should have a higher prevalence on patients diagnosed as having probable $\mathrm{AD}$, we decided to 1) involve a number of specialties in classifying the groups, 2) use fundus photographs as a means of assessing ON degeneration, 3) mask the reader as to the identity or diagnosis of the patient, and 4) ask the 
masked reader to a) measure $\mathrm{c} / \mathrm{d}$ ratios and b) rate the presence or absence of optic atrophy in the patients.

\section{Methods}

\section{Subjects}

The probable AD group was selected from patients followed in the Neurology Service at Bay Pines Veterans Administration Medical Center. The control group consisted of patients at Bay Pines Veterans Administration Medical Center with no neurological disease as verified by neurological history and examination. For the purpose of this study, patients were classified as either 1) probable AD or 2) normal. We photographed the ONs of 13 patients (23ONs) with probable $\mathrm{AD}$ and 15 normal patients (26 ONs). All subjects were 40 years of age or older. All subject selection procedures and study procedures were approved by the institutional review board on human subjects of Bay Pines Veterans Administration Medical Center and complied with the Declaration of Helsinki.

\section{Diagnostic criteria}

Diagnosis of probable $\mathrm{AD}$ or normal was made by a neurologist using the criteria proposed by McKhann et al. [1]. Namely, probable $\mathrm{AD}$ patients exhibited (1) clinically observed dementia, (2) evidence of deficit in two or more cognitive areas, (3) no disturbance of consciousness, and (4) absence of other disease which in and of themselves could account for the cognitive losses. AD had onset after 40 years of age. Differentiation between the AD patients and patients with other dementias, e.g., MID, included the absence of evidence of infarcts on computerized tomography and normal scores on the Hachinski Ischemic Scale [10]. Normal patients showed no evidence of dementia or neurological disease on any test. Each experimental subject had negative laboratory results on the following: Serum Chemistry Profile (SMA-20), Blood Cell Count with Differential (CBC), Syphilis Serology (VDRL), Vitamin B-12 Serum Level, Folate Serum Level, and Thyroid Function (TSH, T4, T3).

\section{Test procedures}

Informed consent was obtained from each patient or their guardian. Patients were allowed to withdraw from the study at any time. There were no withdrawals.

Patients who agreed to participate in the study received an optometric examination. Patients with lenticular opacities, corneal problems that made viewing into the eye to view the ON difficult were excluded from the study. Patients were excluded from the study if either their medical chart indicated a history of glaucoma, including low tension glaucoma, an optometric examination at the time of photography suggested glaucomatous findings, i.e., elevated intraocular pressure or narrowed angles, or their corrected visual acuity was worse than $20 / 40(6 / 12 ; 0.5)$. Those patients who could not cooperate with the optometric examination and photography were excluded from the study.

The ONs of patients meeting the criteria of the investigation were photographed. Photographs were taken of the ONs through dilated pupils using a Zeiss (Thornwood, New York) fundus camera and Kodachrome film (Eastman Kodak, Rochester, NY). The single fundus image subtended approximately 30 degrees. The slides of each patient's optic disks were assigned a separate randomly selected subject number for each eye. Thus eyes of the same patient did not have sequential numbers.
The numbered slides were evaluated by an ophthalmologist masked as to the diagnosis of the patients. The ophthalmologist measured the horizontal and vertical c/d ratios (often abnormal in optic nerve atrophy) [11]. Measurement of $\mathrm{c} / \mathrm{d}$ ratios was made using color changes to define the cup (i.e., the color cup). The ONs were rated as normal, questionably normal, or definitely abnormal with clear evidence of ON atrophy. The ophthalmologist was invited to comment on what about the nerve appeared abnormal $[12,13]$.

Statistical Analysis: The ratings and comments were forwarded to the investigator who served as statistician on the project. He collated the patient identification information with the ophthalmologist's ratings and conducted the statistical analyses. Analyses were conducted using the Statistical Analysis System (SAS; SAS Institute Inc., 2005). Analyses of $\mathrm{c} / \mathrm{d}$ ratios was conducted using a t-test for independent samples. Comparison of $\mathrm{ON}$ ratings was conducted using a 2 (normal versus probable $\mathrm{AD}$ ) x 3 (normal vs probable vs definitely abnormal) contingency table. The significance of the comparison was evaluated using the chi-squared statistic $\left(\chi^{2}\right)$.

\section{Results}

The mean ages of the two groups did not differ significantly; the mean age of the patients with probable $\mathrm{AD}$ was $75+9.83$ and of the normal patients $76.6+13.53$ years. The characteristics of the normal and probable $\mathrm{AD}$ patient are presented in (Tables 1,2), respectively.

The $\mathrm{c} / \mathrm{d}$ ratios did not differ between the two groups. The horizontal $\mathrm{c} / \mathrm{d}$ ratio was $0.44+0.13$ in the eyes of normal patients compared to $0.46+0.007$ in the eyes of probable AD patients $(\mathrm{p}>0.10)$. Vertical $c / d$ ratios were $0.41+0.15$ and $0.46+0.12$ for the eyes of normal and probable AD patients respectively $(\mathrm{p}>0.10)$.

The frequency of ratings of definite $\mathrm{ON}$ atrophy was greater in the probable $\mathrm{AD}$ group than the normal group. One eye of one normal patient was rated as atrophied while eight eyes of seven probable $\mathrm{AD}$ patients were rated as atrophied. For statistical evaluation we classified questionable $\mathrm{ONs}$ as normal and used chi-squared $\left(\chi^{2}\right)$ analysis for 2 $\mathrm{x} 2$ contingency tables for analysis by eye and patient respectively. The ratings differed $\left(\chi^{2}=5.86, p<0.015\right.$ for a comparison of eyes; $\chi^{2}=5.45$, $\mathrm{p}<0.019$ for comparison by subjects). ON atrophy was more frequent in probable $\mathrm{AD}$ than normal patients.

\begin{tabular}{|c|c|c|c|c|}
\hline Subject & Sex & Age & Optic Atrophy Right & Optic Atrophy Left \\
\hline 1 & M & 75 & NO & YES \\
\hline 2 & M & 69 & NO & NO \\
\hline 3 & M & 67 & NO & NO \\
\hline 4 & M & 73 & NO & NO \\
\hline 5 & M & 71 & NO & NO \\
\hline 6 & M & 57 & NO & NO \\
\hline 7 & M & 67 & NO & NO \\
\hline 8 & M & 56 & NO & NO \\
\hline 9 & M & 71 & NO & NO \\
\hline 10 & M & 76 & NO & NO \\
\hline 11 & M & 91 & NO & NO \\
\hline 12 & M & 96 & Not Tested & Not Tested \\
\hline 13 & M & 95 & Not Tested & Not Tested \\
\hline 14 & M & 94 & NO & NO \\
\hline 15 & M & 91 & & \\
\hline
\end{tabular}

Table 1: Subject Identification Information:Normal Control Group. 
Citation: Vernon Odom J, Russell Nelson T, Arnold Adler S, Cruz AR, McNinch DD (2014) Examination Of Optic Nerves Using Fundus Photography: Comparison of Patients with Alzheimer's Disease with Elderly Normals. J Ophthalmic Clin Res 1: 003.

- Page 3 of $4 \cdot$

\begin{tabular}{|c|c|c|c|c|c|c|c|}
\hline Subject & Sex & Age & Mini-Mental State Score & Cat-Scan of the Brain & Electroencephalography & Optic AtrophyRight & Optic Atrophy left \\
\hline 1 & M & 80 & ${ }^{*}$ Mild & Moderate cerebral atrophy & Within normal limits & yes & no \\
\hline 2 & $M$ & 73 & 0 & Moderate cerebral atrophy & - & no & no \\
\hline 3 & M & 67 & 23 & $\begin{array}{l}\text { Mild to moderate cerebral } \\
\text { atrophy }\end{array}$ & Within normal limits & no & no \\
\hline 4 & M & 65 & 0 & $\begin{array}{l}\text { Diffuse cerebral atrophy, mod- } \\
\text { erate ventricular dilation }\end{array}$ & $\begin{array}{l}\text { Moderate abnormality due to diffuse } \\
\text { slowing, compatible with bilateral brain } \\
\text { dysfunction }\end{array}$ & yes & no \\
\hline 5 & $M$ & 72 & 27 & Cerebral atrophy & - & yes & no \\
\hline 6 & M & 83 & $\begin{array}{c}21 \\
\text { *Moderate }\end{array}$ & $\begin{array}{l}\text { Mild to moderate cerebral } \\
\text { atrophy }\end{array}$ & - & yes & yes \\
\hline 7 & M & 69 & * & Within normal limits for age & $\begin{array}{l}\text { Moderate abnormality due to theta } \\
\text { slowing, consistent with bilateral brain } \\
\text { dysfunction }\end{array}$ & yes & no \\
\hline 8 & M & 76 & * & Moderate cortical atrophy & - & no & yes \\
\hline 9 & $\mathrm{~F}$ & 74 & 11 & Cerebral atrophy & - & no & no \\
\hline 10 & M & 72 & 9 & $\begin{array}{l}\text { Generalized cerebral and } \\
\text { cerebellar atrophy }\end{array}$ & - & no & no \\
\hline 11 & M & 92 & 12 & $\begin{array}{l}\text { Moderate frontal and parietal } \\
\text { atrophy }\end{array}$ & $\begin{array}{l}\text { Moderate abnormality due to diffuse slow- } \\
\text { ing particularly over temporal regions }\end{array}$ & - & no \\
\hline 12 & M & 96 & 7 & $\begin{array}{l}\text { Cerebral atrophy throughout } \\
\text { frontal and temporal parietal } \\
\text { areas moderate ventricular } \\
\text { dilatation }\end{array}$ & Diffuse slowing & - & no \\
\hline 13 & M & 64 & 0 & $\begin{array}{l}\text { Significant cerebral atrophy } \\
\text { mainly in the frontal and } \\
\text { parietal lobes, dilatation of the } \\
\text { lateral ventricles, findings were } \\
\text { nonspecific }\end{array}$ & $\begin{array}{l}\text { Mildly abnormal; diffuse slowing and mild } \\
\text { suppression along with some triphasic } \\
\text { waves }\end{array}$ & - & yes \\
\hline
\end{tabular}

Table 2: Subject Identification Information:Alzheimer's Subjects.

\section{Discussion}

ON degeneration is often detectable on ophthalmoscopic examination. We wished to test the hypothesis that ON degeneration should have a higher prevalence in patients diagnosed as having probable $\mathrm{AD}$ on ophthalmoscopic examination. Unfortunately studies involving probable $\mathrm{AD}$ patients are difficult for several reasons. First, those with moderate to severe probable AD may have difficulty in cooperating with study demands. Second, experimenters' who are knowledgeable about the hypothesis may be biased. Third, one must exclude other causes of dementia or of ON atrophy, e.g., MID or glaucoma to be sure that the classifications of probable AD are accurate [14].

We determined that in a carefully selected group of probable $\mathrm{AD}$ and normal patients, a masked, skilled clinician detected a greater frequency of definitely atrophied ONs in the patients with probable $\mathrm{AD}$ than in an age-matched control group. However, measurement of $\mathrm{c} / \mathrm{d}$ ratios using the color cup made by the same clinician failed to show a difference between the normal patients and those with probable $\mathrm{AD}$ in their $\mathrm{c} / \mathrm{d}$ ratios. We will discuss each of these points and their implications.

Unlike Tsai et al. [9], we did not find statistically significant differences in the mean $\mathrm{c} / \mathrm{d}$ ratios between probable $\mathrm{AD}$ and normal patients. However, we did find a difference in frequency of rated $\mathrm{ON}$ atrophy in the two groups. Tsai's c/d measurements were based on depth measurements of the cup. Without stereo photographs our own measurements were be based on the cup as defined by color and pallor differences of the disc [11-13]. Tsai et al. [9] also failed to find a statistically significant difference between probable $\mathrm{AD}$ and normal patients using disc area and pallor area, a measure more analogous to our own. We found that the presence of $\mathrm{ON}$ atrophy was asymmetric being greater in one eye than the other in most patients. Tsai et al. [9] did not make a similar observation likely because they only examined one eye of each patient. In brief, the color or pallor differences in the ON head appear to be insufficient to differentiate probable AD from normal patients. However, when other information such as depth information from an automated ON head analyzer or, perhaps, stereo photographs are used c/d ratios may distinguish groups of patients with probable $\mathrm{AD}$ from normal patients.

Even using only standardized ON photographs, the patients with probable $\mathrm{AD}$ showed a higher incidence of $\mathrm{ON}$ atrophy than normals of the same age. When an ophthalmologist is permitted to use all the information in the photograph to make such judgments, 7 of $13 \mathrm{AD}$ patients show definite ON atrophy while only 1 of 15 normal patients show definite ON atrophy. In reviewing the ophthalmologist's comments, it is clear that vessel changes which indicated a deep cup, narrowed vessels, ON rim pallor and peripapillary atrophy were all factors used in making the judgment of definite ON atrophy. All these factors have been shown to be important in detecting ON atrophy $[12,13]$. We might also note that ON atrophy is more difficult to judge from photographs than from fundoscopy. Therefore, it is possible that the difference in the frequency of $\mathrm{ON}$ atrophy between probable $\mathrm{AD}$ and normal patients may be greater than we observed.

The presence of ON atrophy in living patients with probable $\mathrm{AD}$ observed in the present study and in Tsai et al. [9] study emphasizes the importance of sensory deficits in identifying and understanding the progression of $\mathrm{AD}$. Postmortem studies of patients with definite 
$\mathrm{AD}$ have shown that most have $\mathrm{ON}$ atrophy $[2,3]$. Consistent with this visual deficit of varying types and severity are present in up to $90 \%$ of AD patients [4-8]. Most importantly, statistical analysis indicates that the presence of visual deficits account for up to $50 \%$ of the variance in ability to perform low level cognitive tasks in $\mathrm{AD}$ patients [8].

In summary, the information derived from this study should prove helpful to health care professionals who must consider the diagnosis of $\mathrm{AD}$, especially in those $\mathrm{AD}$ patients with visual complaints. $\mathrm{ON}$ atrophy could be observed in a standard dilated ophthalmoscopic examination in many patients with $\mathrm{AD}$. The frequency of $\mathrm{ON}$ atrophy was much greater in patients with probable $\mathrm{AD}$ than age matched controls.

\section{References}

1. McKhann G, Drachman D, Folstein M, Katzman R, Price D, et al. (1984) Clinical diagnosis of Alzheimer's disease: report of the NINCDS-ADRDA Work Group under the auspices of Department of Health and Human Services Task Force on Alzheimer's Disease.Neurology 34: 939-944.

2. Hinton DR, Sadun AA, Blanks JC, Miller CA (1986) Optic-nerve degeneration in Alzheimer's disease.N Engl J Med 315: 485-487.

3. Sadun AA1, Bassi CJ (1990) Optic nerve damage in Alzheimer's disease. Ophthalmology 97: 9-17.

4. Sadun AA, Borchert M, DeVita E, Hinton DR, Bassi CJ (1987) Assessment of visual impairment in patients with Alzheimer's disease.Am J Ophthalmol 104: 113-120.
5. Cronin-Golomb A1, Corkin S, Rizzo JF, Cohen J, Growdon JH, et al. (1991) Visual dysfunction in Alzheimer's disease: relation to normal aging.Ann Neurol 29: 41-52.

6. Rizzo JF 3rd1, Cronin-Golomb A, Growdon JH, Corkin S, Rosen TJ, et al. (1992) Retinocalcarinefunction in Alzheimer's disease. A clinical and electrophysiological study.Arch Neurol 49: 93-101.

7. Cronin-Golomb A (1995) Vision in Alzheimer's disease.Gerontologist 35: 370-376.

8. Bassi CJ1, Solomon K, Young D (1993) Vision in aging and dementia.Optom Vis Sci 70: 809-813.

9. Tsai CS1, Ritch R, Schwartz B, Lee SS, Miller NR, et al. (1991) Optic nerve head and nerve fiber layer in Alzheimer's disease.Arch Ophthalmol 109: 199204.

10. Hachinski VC, Lassen NA, Marshall J (1974) Multi-infarct dementia. A cause of mental deterioration in the elderly.Lancet 2: 207-210.

11. Carpel EF, Engstrom PF (1981) The normal cup-disk ratio.Am J Ophthalmol 91: 588-597.

12. Jonas JB1, Fernández MC, Naumann GO (1991) Parapapillary atrophy and retinal vessel diameter in nonglaucomatous optic nerve damage. Invest Ophthalmol Vis Sci 32: 2942-2947.

13. Trobe JD, Glaser JS, Cassady JC (1980) Optic atrophy. Differential diagnosis by fundus observation alone.Arch Ophthalmol 98: 1040-1045.

14. McKhann G, Drachman D, Folstein M, Katzman R, Price D, et al. (1984) Clinical diagnosis of Alzheimer's disease: report of the NINCDS-ADRDA Work Group under the auspices of Department of Health and Human Services Task Force on Alzheimer's Disease.Neurology 34: 939-944. 